EXTENDED REPORT

\title{
The treatment of acute dacryocystitis using laser assisted endonasal dacryocystorhinostomy
}

\author{
S Morgan, M Austin, H Whittet
}

Br J Ophthalmol 2004;88:139-141

See end of article for authors' affiliations .....................

Correspondence to: Mr Heikki Whittet, Singleton Hospital, Swansea SA2 8QA, UK heikki.whittet@ swansea-tr.wales.nhs.uk

Accepted for publication 14 April 2003

\begin{abstract}
Aims: To determine whether acute dacryocystitis complicated by abscess formation can be successfully treated using laser assisted endonasal dacryocystorhinostomy.

Methods: A protocol was adopted for the management of acute dacryocystitis presenting to an ophthalmology department. All patients were assessed jointly by an ophthalmologist and otolaryngologist for their suitability for primary internal drainage via a nasal endoscopic approach. All suitable patients during the study period August 1999 to November 2000 were managed by intravenous antibiotics and holmium:YAG laser dacryocystorhinostomy.

Results: Nine patients were studied (mean age 72 years (range 38-82 years), three men, six women). ?A history of chronic epiphora was found in $78 \%$ of patients, and recurrent nasolacrimal infections in the ?same $78 \%$. Resolution of symptoms and signs of acute dacryocystitis occurred in all nine patients. ?No recurrence of acute dacryocystitis occurred during the median follow up period of 11 months ?(range 6-31 months). Ostium patency defined as the absence of epiphora and the observation of irrigated lacrimal fluorescein at the ostium was achieved in $67 \%$ of patients. Epiphora recurred in 33\% of cases.

Conclusion: Laser assisted endonasal dacryocystorhinostomy is an effective primary treatment in cases of acute dacryocystitis complicated by abscess formation. In addition, pre-existing symptoms of epiphora and recurrent nasolacrimal infections are relieved in the majority of patients.
\end{abstract}

$\mathrm{T}$ he conventional treatment of acute dacryocystitis with abscess formation includes the use of warm compresses, systemic antibiotics, percutaneous drainage of the abscess, and external dacryocystorhinostomy (DCR) following resolution of the acute infection. ${ }^{1}$ This approach, however, may result in complications from cutaneous fistula formation, risk of recurrent infection before DCR can be performed, prolonged infection due to poor antibiotic abscess penetration, and the adverse effects of extended systemic antibiotic use. In addition, external DCR can result in cutaneous scar formation and may disrupt medial canthal anatomy. ${ }^{2}{ }^{3}$ Lee and Woog have previously described an endonasal approach to performing DCR as a primary treatment of acute dacryocystitis with abscess formation that was effective in resolving symptoms of epiphora and had an anatomical success rate of $83 \%$ as defined by free irrigation through the lacrimal system. ${ }^{4}$ Primary acute endonasal DCR offers potential advantages over standard treatment with rapid improvement in pain, earlier resolution of infection, and the economic benefits of reduced patient length of stay without the need for later readmission for external or indeed endonasal DCR. ${ }^{5}$ In addition, endonasal endoscopy allows inspection of nasal anatomy and the correction of abnormalities of the nasal septum or middle turbinate that may predispose to failure. However, the nasal mucosal inflammation present in acute dacryocystitis can result in significant haemorrhage during incisions of the lateral mucosa to create an ostium and drain the abscess. The holmium:YAG laser can be used to ablate soft tissues and bone at a selected site with minimal haemorrhage, ${ }^{6}$ and therefore offers potential advantages over standard surgical incisions when creating the ostium in these circumstances. The aim of this study was to prospectively evaluate the use of the holmium:YAG laser in the primary treatment of acute dacryocystitis with abscess formation.

\section{PATIENTS AND METHODS}

Patients presenting to the ophthalmology department at Singleton Hospital, Swansea, with acute dacryocystitis and lacrimal sac abscess between August 1999 and November 2000 were assessed jointly by an ophthalmologist and otolaryngologist for their suitability for primary internal drainage via a nasal endoscopic approach. Preoperative assessment included complete eye and intranasal examination. Exclusion criteria included symptoms or signs such as blood stained tears or a hard mass suggesting possible lacrimal sac neoplasia. All suitable patients were initially managed with intravenous antibiotics and informed consent was obtained before surgery.

Laser assisted dacryocystorhinostomy was performed under either general or local anaesthesia. Nasal mucosal preparation in both instances involved the use of nasal packs applied after anaesthetic induction and soaked with 5\% cocaine solution and 1:1000 adrenaline. Additional infiltration of the lateral nasal wall was only performed when not utilising general anaesthesia, and was achieved with a solution of 1:80000 adrenaline and 2\% lignocaine. Abnormalities of the septum or middle turbinate likely to increase the risk of failure due to occlusion of the ostium or synechiae formation were corrected conventionally and endoscopically.

Where possible an endoilluminator was placed via the superior or inferior canaliculus into the lacrimal sac, and the lacrimal fossa was identified intranasally by transillumination (fig 1). When this proved impossible as a result of marked oedema and cellulitis, anatomical endonasal landmarks were used to localise the nasolacrimal apparatus. The anterior end of middle turbinate, the posterior margin of the frontal process of maxilla, and the swelling that accompanies the nasolacrimal abscess endonasally were used for this purpose. A holmium:YAG laser (Coherent Laser Systems) 


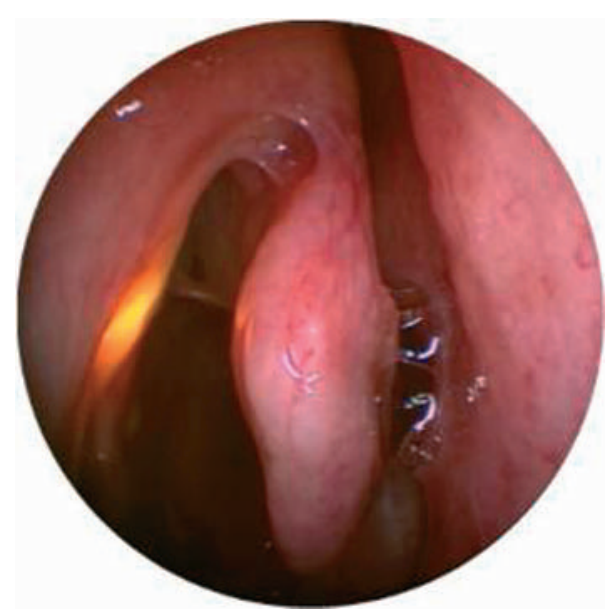

Figure 1 The endoilluminator identifies the position of the nasolacrimal sac within the lacrimal fossa. Note its position immediately lateral to anterior end of middle turbinate and adjacent to the posterior border of the frontal process of maxilla.

was aimed at the site of transillumination (or the positioning of the nasolacrimal sac as determined above) of the lateral nasal mucosa using the helium:neon aiming beam at its lowest setting. The laser was used at a power setting of $22 \mathrm{~W}$ until the creation of an ostium from the nasal mucosa into the lacrimal sac was indicated by the rush of sac contents into the nasal cavity (figs 2 and 3). Remaining lacrimal sac contents were then removed via suction passed endonasally. Silicone tubes were introduced where possible via both canaliculi and secured intranasally with a plastic sleeve and silver ligaclip, to provide stenting of the lacrimal drainage system, and were then left in situ until mucosal healing had finished, as determined endoscopically. If additional septal, middle turbinate, or ethmoid surgery was performed, the nasal cavity was packed with Merocel $8 \mathrm{~cm}$ packs to minimise postoperative bleeding. If no additional procedure was performed, no packs were used. When used the nasal packs were removed 24 hours postoperatively and the patient discharged when the cutaneous inflammation appeared to be subsiding.

Postoperatively, patients were given chloramphenicol eye drops and oral antibiotic treatment was continued for a further 10 days. Outpatient review took place at approxi-

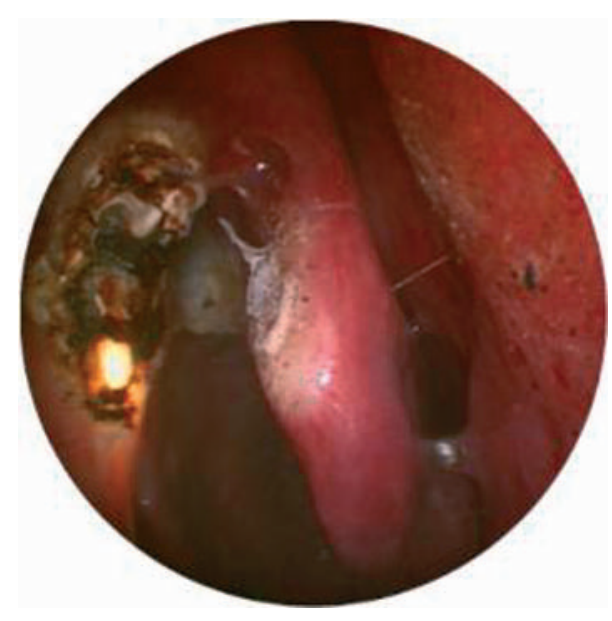

Figure 2 The holmium:YAG laser has created a stoma to the nasolacrimal sac. Note white bone dust created from laser action.

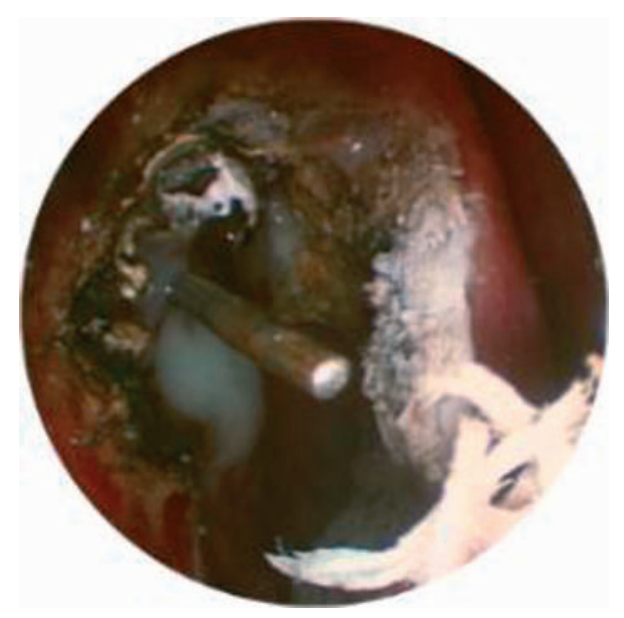

Figure 3 A nasolacrimal probe passed into the nasal cavity via the inferior canaliculus. Residual pus may be seen within the marsupialised nasolacrimal sac.

mately 10 days, 6 weeks, and 6 months postoperatively. Evaluation included assessment for symptoms of epiphora, air reflux, and lacrimal system irrigation with fluorescein followed by endoscopic examination of the endonasal nasolacrimal stoma and nasal cavity. Any sign of granulation tissue formation at the site of the stoma prompted aggressive cauterisation with silver nitrate, debulking, and topical application of Triadcortyl ointment.

\section{RESULTS}

Nine patients were studied with a mean age of 72 years (table 1). Three men and six women were included in the study. The median follow up period was 11 months (range 631 months). A history of chronic epiphora was found in $78 \%$ of patients, and symptoms suggesting recurrent nasolacrimal infections in the same $78 \%$. No patients had a history of previous nasolacrimal surgery. One patient had a medial canthal cutaneous fistula on presentation. During surgery, the lacrimal fossa could not be identified by transillumination in $78 \%$ of cases and so anatomical landmarks were used for this purpose. A patent ostium was present after the surgical procedure in all patients.

Resolution of symptoms and signs of acute dacryocystitis occurred in all nine patients. Pain was markedly relieved by day 1 in all cases, followed by resolution of medial canthal erythema and oedema within 1 week. No recurrence of acute dacryocystitis occurred during the follow up period. Ostium patency defined as the absence of epiphora, air reflux on nose blowing, and the observation of irrigated lacrimal fluorescein at the ostium was achieved in six of the nine patients $(67 \%)$. Symptoms of epiphora recurred in three cases $(33 \%)$ and endoscopic nasal examination revealed stenosis of the ostium with fibrous tissue in these patients.

\section{DISCUSSION}

The use of external dacryocystorhinostomy has been considered to be contraindicated in acute dacryocystitis because of the risk of spreading infection through tissue planes, septicaemia, and exacerbating inflammation. ${ }^{7}$ An endonasal route for DCR would be expected to minimise these risks by allowing the lacrimal sac abscess to be approached without the involvement of non-infected and less inflamed tissue planes. This rationale is borne out by the lack of clinical evidence of spread of infection beyond the lacrimal drainage system in our series. 


\begin{tabular}{|c|c|c|c|c|c|c|}
\hline $\begin{array}{l}\text { Patient } \\
\text { No }\end{array}$ & $\begin{array}{l}\text { Age } \\
\text { (years) }\end{array}$ & Sex & $\begin{array}{l}\text { History of recurrent } \\
\text { dacryocystitis or } \\
\text { epiphora? }\end{array}$ & $\begin{array}{l}\text { Cutaneous fistula } \\
\text { present? }\end{array}$ & $\begin{array}{l}\text { Duration of follow } \\
\text { up (months) }\end{array}$ & Ostial patency? \\
\hline 1 & 75 & $F$ & yes & no & 9 & no \\
\hline 2 & 81 & $\mathrm{~F}$ & yes & yes & 9 & yes \\
\hline 3 & 80 & $\mathrm{~F}$ & yes & no & 6 & yes \\
\hline 4 & 82 & $\mathrm{~F}$ & yes & no & 11 & yes \\
\hline 5 & 76 & $M$ & no & no & 27 & yes \\
\hline 6 & 66 & $M$ & yes & no & 31 & yes \\
\hline 7 & 72 & $\mathrm{~F}$ & yes & no & 30 & no \\
\hline 8 & 38 & $M$ & no & no & 21 & no \\
\hline 9 & 82 & $\mathrm{~F}$ & yes & no & 6 & yes \\
\hline
\end{tabular}

Decompression and drainage of the abscess would be expected to facilitate resolution of the symptoms and signs of acute dacryocystitis. All patients in our study reported a marked reduction in pain the day following decompression. In addition, erythema and oedema rapidly resolved over the week following surgery. Although not specifically an aim of our study, this rapid improvement might be expected to reduce a patient's length of stay in hospital, as well as reducing the total dosage of analgesics and antibiotics required in their management. Additional economic benefits could also be realised by removing the need for readmission for external DCR.

Ostium patency was achieved in $67 \%$ of cases during follow up. This is less than other reports of endonasal dacryocystorhinostomy and may reflect the presence of acute inflammation promoting restenosis. ${ }^{38}$ The three patients who had recurrence of their epiphora did not develop further episodes of cute dacryocystitis. Lee and Woog found a similar picture, and speculated that this may reflect scarring and obliteration of the lacrimal sac abscess cavity after surgical drainage. All three patients in our series elected to have a surgical ostium revision with division of scar tissue and reconstitution of the stoma which resulted in the relieving of their epiphora during the follow up period.

In summary, we suggest that laser assisted endonasal dacryocystorhinostomy is an effective primary treatment in cases of acute dacryocystitis complicated by abscess formation. In addition, pre-existing symptoms of epiphora and recurrent nasolacrimal infections are relieved in the majority of patients.

\section{Authors' affiliations}

S Morgan, Department of Ophthalmology, University Hospital of Wales, Cardiff CF14 4XW, UK

M Austin, Department of Ophthalmology, Singleton Hospital, Swansea SA2 8QA, UK

H Whittet, Department of Otorhinolaryngology, Singleton Hospital,

Swansea SA2 8QA, UK

\section{REFERENCES}

1 Cahill KV, Burns JA. Management of acute dacryocystitis in adults. Ophthal Plast Reconstr Surg 1993;9:38-41.

2 Massaro BM, Gonnering RS, Harris GJ. Endonasal laser dacryocystorhinostomy. A new approach to nasolacrimal duct obstruction. Arch Ophthalmol 1990;108:1172-6.

3 Woog JJ, Metson R, Puliafito CA. Holmium:YAG endonasal laser dacryocystorhinostomy. Am J Ophthalmol 1993;116:1-10.

4 Lee TS, Woog JJ. Endonasal dacryocystorhinostomy in the primary treatment of acute dacryocystitis with abscess formation. Ophthal Plast Reconstr Surg 2001;17:180-3.

5 Whittet HB, Shun-Shin GA, Awdry P. Functional endoscopic transnasal dacryocystorhinostomy. Eye 1993;7:545-9.

6 Sadiq SA, Ohrlich S, Jones NS, et al. Endonasal laser dacryocystorhinostomy-medium term results. Br J Ophthalmol 1997;81:1089-92.

7 Coden DJ, Hornblass A, Haas BD. Clinical bacteriology of dacryocystitis in adults. Ophthal Plast Reconstr Surg 1993;9:125-31.

8 Kong YT, Kim TI, Kong BW. A report of 131 cases of endoscopic laser lacrimal surgery. Ophthalmology 1994;101:1793-800. 